\title{
ABO Blood Group and Outcomes in Patients with COVID-19 Admitted in the Intensive Care Unit (ICU): A Retrospective Study in a Tertiary-Level Hospital in Bangladesh
}

\author{
Mohammad Rabiul Halim ${ }^{\text {'** }}$ \\ Shuvajit Saha ${ }^{2, *}$

*These authors contributed equally to this work

Correspondence: Mohammad Delwer Hossain Hawlader

Email mohammad.hawlader@northsouth. edu
Purpose: The world is heavily suffering from the COVID-19 pandemic for more than a year, with over 191 million confirmed cases and more than 4.1 million deaths to date. Previous studies have explored several risk factors for coronavirus disease 2019 (COVID19), but there is still a lack of association with ABO blood type. This study aimed to find out the relationship between the ABO blood group and COVID-19 outcomes in Bangladesh.

Subjects and Methods: This retrospective cross-sectional study was conducted in the intensive care unit (ICU) of a tertiary-level COVID-dedicated hospital in Dhaka city, Bangladesh, between April 2020 and November 2020. Records from 771 critically ill patients were extracted who were confirmed for COVID-19 by reverse transcriptasepolymerase chain reaction (RT-PCR) assay, and blood grouping records were available in the health records.

Results: The blood groups were $37.35 \%, 17.38 \%, 26.46 \%$, and $18.81 \%$ for $\mathrm{A}, \mathrm{B}, \mathrm{AB}$, and $\mathrm{O}$ type, respectively. Clinical symptoms were significantly more common in patients with blood type A $(p<0.05)$. Patients with blood type A had higher WBC counts and peak serum ferritin levels and both were statistically significant $(p<0.001)$. Patients with blood type A had a greater need for supplemental oxygen, and they were more likely to die in comparison to the patients with other blood types $(p<0.05)$. In multivariable analysis, our primary outcome death was significantly associated with blood type A (AOR: $3.49,95 \% \mathrm{CI}$ : 1.57-7.73) while adjusting for age, male gender, and non-communicable diseases.

Conclusion: Based on this study results, it can be concluded that the COVID-19 patients with blood type A have a higher chance of death and other complications. The authors recommend blood grouping before treating the COVID-19 patients, and healthcare workers should prioritize treating the patients based on that result.

Keywords: COVID-19, ICU, ABO blood group, Bangladesh

\section{Introduction}

The world is suffering a heavy toll from the COVID-19 pandemic, with over 191 million confirmed cases and nearly 4.1 million deaths globally; ${ }^{1}$ irrespective of age and sex, especially in older adults with comorbidities, such as cardiovascular and cerebrovascular diseases and diabetes. ${ }^{2,3}$ Bangladesh has also witnessed more than a million confirmed cases and around 18,000 deaths. ${ }^{4}$ Currently, the country is passing its third wave of community transmission, with a steep rise in both case 
numbers and deaths that has caused a deleterious impact on the national health system and its economy with devastating consequences. ${ }^{5}$

The status of COVID-19 infection has antecedently been shown to be linked with the ABO blood type. ABO blood type plays a significant role in various illnesses, like oncological, cardiovascular, and certain infectious and non-infectious diseases. ${ }^{6}$ To name a few examples, studies have reported that blood group $\mathrm{O}$ substantially reduces the risk of hepatitis B. Simultaneously, rotaviral gastroenteritis was more common in patients with blood type $A$ and less frequent in patients with blood type B. ${ }^{7,8}$ It was also observed that people with $\mathrm{AB}$ blood type were 2.5 times more likely to experience dengue hemorrhagic fever than other blood types. ${ }^{9}$ Previous analyses on SARS-CoV-1 have identified a link between the chance of infection with the blood type, in which people with blood group $\mathrm{O}$ had a low risk of infection with SARS-CoV-1. ${ }^{10,11}$

To date, there is not much concrete evidence that has demonstrated a relationship between SARS-CoV-2 with the ABO blood types. Most research has found that individuals with blood group $\mathrm{A}$ are at an elevated risk of infection by the SARS-CoV-2 virus, while blood group $\mathrm{O}$ was less likely to be infected with less severe outcomes. $^{6,12-15}$ Moreover, very few studies were conducted in Bangladesh to find the link between the two. Therefore, this study was conducted to determine the relationship between the $\mathrm{ABO}$ blood type and its outcome with patients infected with SARS-CoV-2.

\section{Methods}

\section{Study Design, Setting, and Participants}

A retrospective cross-sectional study was conducted in the Intensive Care Unit (ICU) of a tertiary-level COVIDdedicated hospital in Dhaka, the capital of Bangladesh. The medical records of 1003 adult patients diagnosed as positive cases of COVID-19 and were admitted in the ICU between April 2020 and November 2020 were reviewed, and data from 771 patients were finally used for analysis. The rest of the data were excluded due to incomplete reports. All the patients who were tested positive for SARSCoV-2 confirmed by RT-PCR assay and had a blood type available in the health records were included in this study.

\section{Variables Collected and Definitions}

The patients' socio-demographics, clinical characteristics including age, gender, $\mathrm{Rh}$ factor, comorbidities, and signs and symptoms were recorded. Comorbidities included in this study were chronic kidney disease (CKD), chronic obstructive pulmonary disease (COPD), diabetes mellitus (DM), hypertension, hypothyroidism, and ischemic heart disease (IHD), and those were analyzed as binary variables. Laboratory data included white blood cell (WBC) count, lymphocyte percentage, peak C-reactive protein (CRP), serum creatinine, lactate dehydrogenase (LDH), and peak serum ferritin. Laboratory findings were categorized as normal, high or low based on the following reference values: WBC: $4-9 \times 10^{9} / \mathrm{L}$, lymphocyte: $20 \%-40 \%$, CRP: $<5 \mathrm{mg} / \mathrm{L}$, S. creatinine: $0.4-1.3 \mathrm{mg} / \mathrm{dl}, \mathrm{LDH}: 140-280 \mathrm{U} / \mathrm{L}, \mathrm{S}$. ferritin: male, $22-336 \mathrm{ng} / \mathrm{mL}$; female, $10-306 \mathrm{ng} / \mathrm{mL}$. All the laboratory data were recorded during ICU admission.

The oxygen therapy mode (received by admitted patients of our study) categorized into a nasal cannula, rebreather mask or facemask, non-invasive ventilation or high-flow nasal cannula (HFNC), and mechanical ventilation was also collected. Data related to the mode of oxygen therapy were recorded during ICU admission. The primary outcome of interest was death in ICU due to complications of COVID19 infection. Other complications included in this study were acute respiratory distress syndrome (ARDS), acute kidney injury (AKI), and shock. ARDS was defined as acute onset, profound hypoxemia with bilateral pulmonary infiltrates, and the absence of left atrial hypertension. AKI was diagnosed according to KDIGO criteria.

\section{Statistical Analysis}

For descriptive analysis, categorical variables were summarized as frequency or percentage. To determine the association between the ABO blood group and other independent variables, Pearson's chi-square test or Fisher's exact test were done as appropriate. Multivariable logistic regression was done for the death variable while adjusting age, male gender, positive Rhesus factor, DM, HTN, CKD, IHD, hypothyroidism, and COPD. A $p$-value of $<0.05$ was considered statistically significant. Data were analyzed by STATA 16, SE version.

\section{Ethical Consideration}

Ethical approval was obtained from the Institutional Review Board (IRB)/Ethical Review Committee (ERC) of North South University, Bangladesh (2020/OR-NSU /IRB-No-0901). The moral principles were set down in the 1964 Declaration of Helsinki, and its later changes were followed. Approval from the appropriate authority has been obtained before data extraction. Patient informed consent was waived as it was a hospital-based, 
Table I Demographics and Clinical Characteristics of Patients with COVID-I9

\begin{tabular}{|c|c|c|c|c|c|}
\hline Variables & Blood Type A & Blood Type B & Blood Type AB & Blood Type O & P-value \\
\hline Frequency $(\mathrm{N})$ & 288 (37.35\%) & I 34 (I7.38\%) & $204(26.46 \%)$ & I 45 (|8.8I\%) & \\
\hline $\begin{array}{l}\text { Age (years) } \\
18-30 \\
31-40 \\
41-50 \\
51-60 \\
>60\end{array}$ & $\begin{array}{l}39(44.32 \%) \\
43(34.96 \%) \\
72(32.73 \%) \\
59(33.52 \%) \\
75(45.73 \%)\end{array}$ & $\begin{array}{l}\text { II (I2.50\%) } \\
23 \text { (I8.70\%) } \\
39 \text { (I7.73\%) } \\
34 \text { (19.32\%) } \\
27 \text { (I6.46\%) }\end{array}$ & $\begin{array}{l}23 \text { (26.14\%) } \\
34 \text { (27.64\%) } \\
65 \text { (29.55\%) } \\
48 \text { (27.27\%) } \\
34(20.73 \%)\end{array}$ & $\begin{array}{l}\text { I5 }(17.05 \%) \\
23 \text { (I8.70\%) } \\
44 \text { (20.00\%) } \\
35 \text { (19.89\%) } \\
28 \text { (17.07\%) }\end{array}$ & 0.46 \\
\hline $\begin{array}{l}\text { Rhesus } \\
\text { Positive } \\
\text { Negative }\end{array}$ & $\begin{array}{c}254(35.08 \%) \\
34(72.34 \%)\end{array}$ & $\begin{array}{c}130(17.96 \%) \\
4(8.51 \%)\end{array}$ & $\begin{array}{c}20 \mathrm{I}(27.76 \%) \\
3(6.38 \%)\end{array}$ & $\begin{array}{c}139(19.20 \%) \\
6(12.77 \%)\end{array}$ & $<0.001$ \\
\hline $\begin{array}{l}\text { Gender } \\
\text { Male } \\
\text { Female }\end{array}$ & $\begin{array}{c}240(38.28 \%) \\
48(33.33 \%)\end{array}$ & $\begin{array}{l}\text { II } 3(18.02 \%) \\
21 \text { (I4.58\%) }\end{array}$ & $\begin{array}{c}162(25.84 \%) \\
42(29.17 \%)\end{array}$ & $\begin{array}{l}112(17.86 \%) \\
33(22.92 \%)\end{array}$ & 0.30 \\
\hline $\begin{array}{l}\text { Comorbidities } \\
\text { Diabetes mellitus } \\
\text { Hypertension } \\
\text { Chronic kidney } \\
\text { disease } \\
\text { IHD } \\
\text { Hypothyroid } \\
\text { COPD }\end{array}$ & $\begin{array}{l}31 \text { (36.90\%) } \\
04(21.05 \%) \\
05(35.71 \%)\end{array}$ & $\begin{array}{l}73(17.14 \%) \\
62(16.53 \%) \\
12(10.43 \%) \\
16(19.05 \%) \\
06(31.58 \%) \\
05(35.71 \%)\end{array}$ & $\begin{array}{c}107(25.12 \%) \\
96(25.60 \%) \\
34(29.57 \%) \\
21(25 \%) \\
04(21.05 \%) \\
01(7.14 \%)\end{array}$ & $\begin{array}{l}16(19.05 \%) \\
05(26.32 \%) \\
03(21.43 \%)\end{array}$ & $\begin{array}{c}0.75 \\
0.79 \\
0.021 \\
\\
0.97 \\
0.20^{*} \\
0.17^{*}\end{array}$ \\
\hline $\begin{array}{l}\text { Signs and } \\
\text { Symptoms }\end{array}$ & & & & & \\
\hline $\begin{array}{l}\text { Fever } \\
\text { Cough } \\
\text { Shortness of } \\
\text { breath }\end{array}$ & $\begin{array}{l}255(37.12 \%) \\
183(41.03 \%) \\
222(39.93 \%)\end{array}$ & $\begin{array}{l}124 \text { (I8.05\%) } \\
76 \text { (I7.04\%) } \\
94 \text { (I6.91\%) }\end{array}$ & $\begin{array}{l}174(25.33 \%) \\
103(23.09 \%) \\
134(24.10 \%)\end{array}$ & $\begin{array}{c}134 \text { (19.5I\%) } \\
84(18.83 \%) \\
106(19.06 \%)\end{array}$ & $\begin{array}{c}0.09 \\
0.038 \\
0.045\end{array}$ \\
\hline Anosmia & 21 (29.58\%) & 9 (12.68\%) & 27 (38.03\%) & 14 (19.72\%) & 0.10 \\
\hline Diarrhea & $23(30.67 \%)$ & $15(20 \%)$ & $21(28 \%)$ & 16 (21.33\%) & $\begin{array}{l}0.64 \\
0.74\end{array}$ \\
\hline $\begin{array}{l}\text { Vomiting } \\
\text { Fatigue }\end{array}$ & $\begin{array}{l}27(36.49 \%) \\
30(44.78 \%)\end{array}$ & $\begin{array}{l}16(21.62 \%) \\
10(14.93 \%)\end{array}$ & $\begin{array}{l}17(22.97 \%) \\
14(20.90 \%)\end{array}$ & $\begin{array}{l}14(18.92 \%) \\
13(19.40 \%)\end{array}$ & $\begin{array}{l}0.74 \\
0.53\end{array}$ \\
\hline $\begin{array}{l}\text { Chest pain or } \\
\text { discomfort }\end{array}$ & 100 (37.74\%) & 46 (I7.36\%) & 69 (26.04\%) & 50 (I8.87\%) & 0.99 \\
\hline Headache & 53 (39.85\%) & 27 (20.30\%) & $4 \mathrm{l}(30.83 \%)$ & 12 (9.02\%) & 0.015 \\
\hline Abdominal pain & $29(38.16 \%)$ & $16(21.05 \%)$ & $16(21.05 \%)$ & 15 (19.74\%) & 0.65 \\
\hline Body ache & 32 (29.63\%) & 20 (I8.52\%) & $23(21.30 \%)$ & $33(30.56 \%)$ & 0.006 \\
\hline
\end{tabular}

Notes: *Fisher's exact test has been done. Bold values denote statistical significance at the $p<0.05$ level.

Abbreviations: IHD, ischemic heart disease; COPD, chronic obstructive pulmonary disease.

retrospective study. All patient's data were accessed and maintained in a confidential manner.

\section{Result}

Table 1 has shown the demographics and baseline characteristics of 771 COVID-positive patients included in this study. The ABO blood group displayed a percentage distribution for A, B, AB, O at 37.35\% (288), 17.38\% (134),
26.46\% (204), 18.81\% (145) respectively. Patients with blood group A had the highest (72.34\%) level of negative Rhesus antigen $(p<0.001)$. Although there were no significant differences in age or gender between the blood types ( $p=0.46$ ), about $45.73 \%$ of the patients with blood type A were in the age group over 60 years. Patients with blood group A had a higher percentage of comorbidities than other groups for the same diseases. The most common 
Table 2 Association Between Laboratory Findings and ABO Blood Group of Patients with COVID-19

\begin{tabular}{|c|c|c|c|c|c|}
\hline Variables & Blood Type A & Blood Type B & Blood Type AB & Blood Type 0 & P-value \\
\hline $\begin{array}{l}\text { WBC Count } \\
\text { Normal } \\
\text { High } \\
\text { Low }\end{array}$ & $\begin{array}{c}85(33.86 \%) \\
202(39.22 \%) \\
01(20.00 \%)\end{array}$ & $\begin{array}{c}40(15.94 \%) \\
94(18.25 \%) \\
0(0.00 \%)\end{array}$ & $\begin{array}{c}56(22.31 \%) \\
\text { I } 46(28.35 \%) \\
2(40.00 \%)\end{array}$ & $\begin{array}{c}70(27.89 \%) \\
73(14.17 \%) \\
2(40.00 \%)\end{array}$ & $<0.001 *$ \\
\hline $\begin{array}{l}\text { Lymphocyte } \\
\text { Normal } \\
\text { High } \\
\text { Low }\end{array}$ & $\begin{array}{c}107(35.91 \%) \\
04(22.22 \%) \\
177(38.90 \%)\end{array}$ & $\begin{array}{l}53(17.79 \%) \\
03(16.67 \%) \\
78(17.14 \%)\end{array}$ & $\begin{array}{c}83(27.85 \%) \\
06(33.33 \%) \\
\text { II5 (25.27\%) }\end{array}$ & $\begin{array}{l}55 \text { (I8.46\%) } \\
05 \text { (27.78\%) } \\
85 \text { (18.68\%) }\end{array}$ & $0.75^{*}$ \\
\hline $\begin{array}{l}\text { Peak CRP } \\
\text { Normal } \\
\text { High }\end{array}$ & $\begin{array}{c}15(33.33 \%) \\
273(37.60 \%)\end{array}$ & $\begin{array}{l}06(13.33 \%) \\
128(17.63 \%)\end{array}$ & $\begin{array}{c}14(31.11 \%) \\
190(26.17 \%)\end{array}$ & $\begin{array}{c}10(22.22 \%) \\
135(18.60 \%)\end{array}$ & 0.72 \\
\hline $\begin{array}{l}\text { S. creatinine } \\
\text { Normal } \\
\text { High }\end{array}$ & $\begin{array}{c}220(36.85 \%) \\
68(39.08 \%)\end{array}$ & $\begin{array}{l}112(18.76 \%) \\
22(12.64 \%)\end{array}$ & $\begin{array}{c}162(27.14 \%) \\
42(24.14 \%)\end{array}$ & $\begin{array}{c}103(17.25 \%) \\
42(24.14 \%)\end{array}$ & 0.07 \\
\hline $\begin{array}{l}\text { LDH }(n=5 \text { I I ) } \\
\text { Normal } \\
\text { High }\end{array}$ & $\begin{array}{c}39(49.37 \%) \\
198(45.83 \%)\end{array}$ & $\begin{array}{l}10(12.66 \%) \\
64(14.81 \%)\end{array}$ & $\begin{array}{l}13(16.46 \%) \\
85(19.68 \%)\end{array}$ & $\begin{array}{l}17(21.52 \%) \\
85(19.68 \%)\end{array}$ & 0.83 \\
\hline $\begin{array}{l}\text { Peak S. ferritin } \\
(n=644) \\
\text { Normal } \\
\text { High }\end{array}$ & $\begin{array}{c}90(36.00 \%) \\
145(36.80 \%)\end{array}$ & $\begin{array}{l}40(16.00 \%) \\
7 \mid(18.02 \%)\end{array}$ & $\begin{array}{l}53(21.20 \%) \\
122(30.96 \%)\end{array}$ & $\begin{array}{l}67(26.80 \%) \\
56(14.21 \%)\end{array}$ & $<0.001$ \\
\hline
\end{tabular}

Notes: *Fisher's exact test has been done. Bold values denote statistical significance at the $p<0.05$ level.

Abbreviations: WBC, white blood cell; CRP, C-reactive protein; S. creatinine, serum creatinine; LDH, lactate dehydrogenase; S. ferritin, serum ferritin.

comorbidities among the patients with blood type A had diabetes mellitus (38.73\%), hypertension (38.13\%), chronic kidney disease (33.04\%), and ischemic heart disease (36.90\%). Hypothyroidism was common in patients with blood type B (31.58\%), while COPD was equal in blood groups B and A (35.71\%). Moreover, chronic kidney disease was significantly associated $(p=0.021)$ with patients positive for COVID-19 with blood group A. Among the signs and symptoms of COVID-positive patients, cough, shortness of breath, and headache were significantly more common in patients with blood type A $\quad(41.03 \%, \quad p=0.038 ; 39.93 \%, \quad p=0.045 ; \quad 39.85 \%$, $p=0.015$; respectively). Patients with blood types A and $\mathrm{O}$ had also suffered from body ache more than other groups (29.63\% and $30.56 \%$ respectively, $p=0.006$ ).

Some laboratory investigations of COVID-positive patients reported significant variations (Table 2). Patients with blood type A had slightly higher WBC counts and peak serum ferritin levels $(39.22 \%, p=0.001 ; 36.80 \%$, $p=0.001$, respectively). A lower level of lymphocyte count $(38.90 \%)$ and a higher level of peak CRP
(37.60\%), Serum creatinine (39.08\%), and LDH $(45.83 \%)$ were also found in patients with blood type A but was not statistically significant.

Variations in oxygen therapy of COVID-19 patients in different blood types have been observed and summarized in Table 3. Patients with blood type A had a greater need for various forms of supplemental oxygen (nasal cannula, facial mask/rebreather mask, mechanical ventilation, highflow nasal cannula/non-invasive ventilation) than patients with other blood types, with the most increased need for mechanical ventilation $(55.68 \%, p=0.002)$.

Table 4 has shown the complications developed from COVID. Among the complications, AKI was substantially correlated with blood types, with blood type A (54.72\%, $p=0.04$ ) being the most common. Patients with blood type A were also more likely to die $(54.44 \%, p=0.002)$. Moreover, $41.31 \%$ and $39.34 \%$ of the patients with blood type A developed ARDS and shock but were not statistically significant.

In multivariable analysis (Table 5), death was significantly associated with blood type A (AOR: $3.49,95 \%$ CI: 
Table 3 Association Between Highest Mode of Oxygen Therapy and ABO Blood Group

\begin{tabular}{|l|c|c|c|c|c|}
\hline Variables & Blood Type A & Blood Type B & Blood Type AB & Blood Type O & P-value \\
\hline Nasal cannula & $46(38.66 \%)$ & $22(18.49 \%)$ & $24(20.17 \%)$ & $27(22.69 \%)$ & \\
Face nask/Non- rebreather mask & $54(35.53 \%)$ & $22(14.47 \%)$ & $54(35.53 \%)$ & $22(14.47 \%)$ & $\mathbf{0 . 0 0 2}$ \\
High-flow nasal cannula/Non-invasive ventilation & $139(33.74 \%)$ & $76(18.45 \%)$ & $111(26.94 \%)$ & $86(20.87 \%)$ & $10(11.36 \%)$ \\
Mechanical ventilation & $49(55.68 \%)$ & $14(15.91 \%)$ & $15(17.05 \%)$ & 10 \\
\hline
\end{tabular}

Note: Bold values denote statistical significance at the $p<0.05$ level.

Table 4 Association Between Complications from COVID-19 and ABO Blood Group

\begin{tabular}{|l|c|c|c|c|c|}
\hline Variables & Blood Type A & Blood Type B & Blood Type AB & Blood Type O & P-value \\
\hline AKI & $29(54.72 \%)$ & $9(16.98 \%)$ & $8(15.09 \%)$ & $7(13.21 \%)$ & $\mathbf{0 . 0 4}$ \\
ARDS & $164(41.31 \%)$ & $71(17.88 \%)$ & $97(24.43 \%)$ & $65(16.37 \%)$ & 0.06 \\
Shock & $120(39.34 \%)$ & $53(17.38 \%)$ & $76(24.92 \%)$ & $56(18.36 \%)$ & 0.79 \\
Death & $49(54.44 \%)$ & $16(17.78 \%)$ & $15(16.67 \%)$ & $10(11.11 \%)$ & $\mathbf{0 . 0 0 2}$ \\
\hline
\end{tabular}

Note: Bold values denote statistical significance at the $p<0.05$ level.

Abbreviations: AKI, acute kidney injury; ARDS, acute respiratory distress syndrome.

Table 5 Univariable and Multivariable Analysis Showing the Association Between Blood Type and Death

\begin{tabular}{|l|c|c|c|c|c|c|}
\hline Blood Type & Unadjusted OR & $\mathbf{9 5 \%} \mathbf{C l}$ & P-value & Adjusted OR & $\mathbf{9 5 \%} \mathbf{C l}$ & P-value \\
\hline $\mathrm{O}$ & Ref & & & Ref & \\
$\mathrm{A}$ & 2.77 & $1.36-5.64$ & $\mathbf{0 . 0 0 5}$ & 3.49 & $1.57-7.73$ \\
$\mathrm{~B}$ & $\mathrm{I}$ & $0.80-4.19$ & 0.15 & 2.14 & $0.05-5.34$ & 0.10 \\
$\mathrm{AB}$ & $\mathrm{I}$ & $0.47-2.46$ & 0.87 & 1.30 & $0.53-3.23$ & 0.57 \\
$\mathrm{Rh}+$ & 2.00 & $0.61-6.59$ & 0.25 & 2.92 & $0.83-10.31$ & 0.09 \\
\hline
\end{tabular}

Notes: Adjusted for age, male gender, presence of positive Rhesus factor, DM, HTN, CKD, IHD, hypothyroidism, and COPD. Bold values denote statistical significance at the $p<0.05$ level.

$1.57-7.73, p=0.002)$ while adjusting for age, male gender, presence of positive Rhesus factor, DM, HTN, CKD, IHD, Hypothyroidism, and COPD.

\section{Discussion}

The present study found that $\mathrm{A}$ was the most common blood type $(37.35 \%)$, followed by $\mathrm{B}$ at $17.38 \%, \mathrm{AB}$ at $26.46 \%$ and $\mathrm{O}$ at $18.81 \%$ among the COVID-infected patients. However, in Bangladesh, $\mathrm{O}$ is the most common blood type (34\%) among the general population, followed by $\mathrm{B}(31 \%)$, A (27\%) and AB (7\%). ${ }^{16}$ This study demonstrated that blood type A was associated with complications and death in ICU admitted COVID-19 patients, whereas patients with blood group $\mathrm{O}$ had suffered fewer complications followed by death due to COVID-19. Similar research has also shown that blood group A was substantially linked to a higher risk of death, ${ }^{17-19}$ while blood type O lowered the risk of COVID-19. ${ }^{17-22}$ Few other studies found no such association between $\mathrm{ABO}$ blood type and severity or death in COVID-positive patients. ${ }^{23-25}$ Although these data highlight that ABO antigens may play a role in the pathophysiology of COVID19 , nevertheless, the mechanism(s) through which these antigens confer vulnerability or protection remain unknown. Infectious agents have been hypothesized to influence human DNA evolution via the natural selection of certain alleles that predispose the population to infection. Through glycosylation, ABO determinants may influence host-pathogen interactions. Anti-A and anti-B antibodies produced naturally may also alter vulnerability to COVID-19 infection. These antibodies may help to slow the spread of SARS-CoV infection and thereby decreases complications and death. ${ }^{19}$

In the present study, among the 771 COVID-positive patients, males were predominant than females. Male cases outnumbered female cases in past research, and males tend to be more extreme or critical condition. ${ }^{26-28}$ Though such predominance of COVID-19 in males was unclear; it has been recently found that specific comorbidities (ie, hypertension, diabetes mellitus, cardiovascular 
disease) can indirectly increase the likelihood of illness or death among males. ${ }^{29}$ However, in some countries, like India, Nepal, Vietnam, and Slovenia, the COVID-19 incident fatality rate is higher in women than in men. ${ }^{30}$ These disparate observations on the association between gender and COVID-19 fatality across countries may reflect insufficient COVID-19 data along geographic regions, biases in COVID-19 identification by gender, or increased risks for females in certain regions due to population factors or the health profiles of those countries. Age is another risk factor of COVID-19, and previous studies have found that the severity of the disease increased with advanced ages. ${ }^{27,28}$ Our research has also shown that about $45.73 \%$ of the patients with blood type A admitted in the ICU were in the age group over 60 years. The sex difference in the COVID-19 fatality rate was significant in the middle age group (40-49) among females in India. ${ }^{31}$ It is critical to utilize the WHO world standard population for international comparisons because countries vary significantly in their population age structure.

Cough, shortness of breath, and headache were found to be significantly more common in patients having blood group A, while myalgia was found to be substantially more common in patients with blood type O. A recent study found that myalgia was significantly lower among the patients with blood type AB. ${ }^{32}$ Similar to the findings of Hoiland et al, ${ }^{33}$ the current study discovered that WBC count was higher in patients with blood group A. Peak S. ferritin was also significantly higher in our study. However, no such relationship has been found in other studies. $^{22,33}$

The need for different methods of oxygen therapy was found to be disproportionately common in individuals with blood type A, with the highest demand for mechanical ventilation compared to other classes. Though to our knowledge, very few studies have tried to find this kind of relationship; in one study, COVID-19-infected patients having blood groups $\mathrm{AB}$ or $\mathrm{A}$ had a higher percentage of the requirement for mechanical ventilation, ${ }^{33}$ while in another study, the blood group $\mathrm{O}$ showed the highest rate requiring artificial respiration. ${ }^{32}$ One possible explanation for these disparate findings is that the latter one of these studies has failed to account for different confounding variables, including comorbidities. Another potential confounding factor is the inclusion of randomly chosen voluntary blood donors for controls, given the chance of group O demographic prevalence resulting from blood collectors collecting group $\mathrm{O}$ donors selectively. ${ }^{34}$
AKI is one of the common complications of COVID19, which occurs due to hemodynamic instability and severe infection by COVID-19. ${ }^{35}$ AKI is substantially correlated with patients with blood type A, according to this study's results. Similarly, the incidence of AKI was significantly higher in the patients with blood type A in the study of Cheng et al, ${ }^{10}$ while no such association was found in another study. ${ }^{36}$

The findings from this study suggested that blood group A is significantly associated with severe disease, causing complications and death, and requires mechanical ventilation. There could have several mechanisms of blood type A leading to a poor prognosis. Individuals with blood type A have shown increased angiotensin-convertingenzyme-1 (ACE-1) activity, making them susceptible to cardiovascular complications and accounts for severe COVID-19. Individuals with blood type A also express high levels of von Willebrand factor (VWF) and factor VIII, contributing to the risk of thromboembolic disease and severe COVID-19. ${ }^{34}$ However, this is a single-centred study, which is a limitation. Multi-centered further surveys are necessary to establish the association between the ABO blood group and outcomes in COVID-positive patients and may provide a strong groundwork for further analysis in this region. Furthermore, the laboratory values are missing for some patients in this study, which has accounted for another limitation for complete analysis. This study provides essential information on the need for oxygen therapy and the risk of death in the COVID-19 positive patients with $\mathrm{ABO}$ blood groups. Additionally, similar previous studies did not consider confounding factors like chronic prior medical disorders, ${ }^{17,19,37}$ which may increase the likelihood and intensity of SARS-CoV-2 infection. One of the main strengths of this study included these confounding factors, which may help future studies to conduct and analyze from a broader perspective.

\section{Conclusion}

In this study, the association of COVID-19 severity with ABO blood groups was evaluated. Notably, blood type A was associated with a higher percentage of severity, complications, and death from COVID-19, whereas blood group $\mathrm{O}$ lessened the risks of complications from COVID-19. Further studies with similar findings in this region can confirm these clinical findings for blood group-specific specialized care, such as more protective personal gears for people with blood type A and aggressive treatment and careful screening for COVID-19 
affect patients with type A blood group. However, because of this study's limitations mentioned above, the findings should be handled carefully. Further studies to verify these findings are strongly emphasized. Meanwhile, the authors of this study urge everyone, irrespective of blood groups, to continue practising protective health measures to combat COVID-19 as a whole.

\section{Acknowledgments}

We would like to convey our heartfelt appreciation for the participants' assistance.

\section{Disclosure}

The authors report no conflicts of interest in this work.

\section{References}

1. WHO Coronavirus (COVID-19) Dashboard. WHO Coronavirus (COVID-19) dashboard with vaccination data; 2021. Available from: https://covid19.who.int/. Accessed July 23, 2021.

2. Almazeedi S, Al-Youha S, Jamal MH, et al. Characteristics, risk factors and outcomes among the first consecutive 1096 patients diagnosed with COVID-19 in Kuwait. EClinicalMedicine. 2020;24:100448. doi:10.1016/j.eclinm.2020.100448

3. Richardson S, Hirsch JS, Narasimhan M, et al. Presenting characteristics, comorbidities, and outcomes among 5700 patients hospitalized with COVID-19 in the New York City Area. JAMA. 2020;323 (20):2052. doi:10.1001/jama.2020.6775

4. WHO. Coronavirus disease (COVID-2019) Bangladesh situation reports; 2021. Available from: https://www.who.int/bangladesh/emer gencies/coronavirus-disease-(covid-19)-update/coronavirus-disease -(covid-2019)-bangladesh-situation-reports. Accessed July 23, 2021.

5. corona.gov.bd. Coronavirus Disease 2019 (COVID-19) Information Bangladesh; 2021. Available from: https://corona.gov.bd/. Accessed July 23, 2021.

6. Fan Q, Zhang W, Li B, Li D-J, Zhang J, Zhao F. Association between ABO blood group system and COVID-19 susceptibility in Wuhan. Front Cell Infect Microbiol. 2020;10:1-7. doi:10.3389/ fcimb.2020.00404

7. Mohammadali F, Pourfathollah A. Association of ABO and Rh blood groups to blood-borne infections among blood donors in Tehran-Iran Iran J Public Health. 2014;43(7):981-989.

8. Elnady HG, Samie OMA, Saleh MT, et al. ABO blood grouping in Egyptian children with rotavirus gastroenteritis. Gastroenterol Rev 2017;3(3):175-180. doi:10.5114/pg.2017.70469

9. Murugananthan K, Subramaniyam S, Kumanan T, Owens L, Ketheesan N, Noordeen F. Blood group AB is associated with severe forms of dengue virus infection. Virus Dis. 2018;29(1):103-105. doi:10.1007/s13337-018-0426-8

10. Cheng Y, Cheng G, Chui $\mathrm{CH}$, et al. ABO blood group and susceptibility to severe acute respiratory syndrome. JAMA. 2005;293 (12):1447-1451. doi:10.1001/jama.293.12.1450-c

11. Cooling L. Blood groups in infection and host susceptibility. Clin Microbiol Rev. 2015;28(3):801-870.

12. Alkout TA, Alkout AM. Original article ABO blood groups among Coronavirus disease 2019 patients. Iberoam J Med. 2020;2:268-274.

13. Zietz M, Zucker J, Tatonetti NP. Testing the association between blood type and COVID-19 infection, intubation, and death. medRxiv. 2020. doi:10.1101/2020.04.08.20058073
14. Göker H, Aladağ-Karakulak E, Demiroğlu H, et al. The effects of blood group types on the risk of COVID-19 infection and its clinical outcome. Turkish J Med Sci. 2020;50(4):679-683. doi:10.3906/sag2005-395

15. Liu N, Zhang T, Ma L, et al. The impact of ABO blood group on COVID-19 infection risk and mortality: a systematic review and meta-analysis. Blood Rev. 2021;48:100785. doi:10.1016/j. blre. 2020.100785

16. Dewan G. Comparative frequency and allelic distribution of $\mathrm{ABO}$ and $\mathrm{Rh}$ (D) blood groups of major tribal communities of southern Bangladesh with general population and their determinants. Egypt J Med Human Genet. 2015;16(2):141-147. doi:10.1016/j.ejmhg.2015.01.002

17. Zhao J, Yang Y, Huang H, et al. Relationship between the ABO blood group and the COVID-19 susceptibility. medRxiv. 2020;73:1-18.

18. Muñiz-Diaz E, Llopis J, Parra R, et al. Relationship between the ABO blood group and COVID-19 susceptibility, severity and mortality in two cohorts of patients. Blood Transfus. 2020;19(1):54. doi: $10.2450 / 2020.0256-20$

19. Ad'hiah AH, Allami RH, Mohsin RH, Abdullah MH, AL-Sa'ady AJR, Alsudani MY. Evaluating of the association between ABO blood groups and coronavirus disease 2019 (COVID-19) in Iraqi patients. Egypt $J$ Med Human Genet. 2020;21(1). doi:10.1186/s43042-020-00097-x

20. Wu Y, Feng Z, Li P, Yu Q. Relationship between ABO blood group distribution and clinical characteristics in patients with COVID-19. Clin Chim Acta. 2020;509:220-223. doi:10.1016/j.cca.2020.06.026

21. Padhi S, Suvankar S, Dash D, et al. Since January 2020 Elsevier has created a COVID-19 resource centre with free information in English and Mandarin on the novel coronavirus COVID- 19. The COVID-19 resource centre is hosted on Elsevier Connect, the company 's public news and information; 2020.

22. Latz CA, DeCarlo C, Boitano L, et al. Blood type and outcomes in patients with COVID-19. Ann Hematol. 2020;99(9):2113-2118. doi:10.1007/s00277-020-04169-1

23. May JE, McGwin G, Gangaraju R, et al. Questioning the association between $\mathrm{ABO}$ type and outcomes in patients with COVID-19. Ann Hematol. 2020;1-2. doi:10.1007/s00277-020-04348-0

24. Barnkob $\mathrm{MB}$, Pottegård $\mathrm{A}$, Støvring $\mathrm{H}$, et al. Reduced prevalence of SARS-CoV-2 infection in ABO blood group O. Blood Adv. 2020;4 (20):4990-4993. doi:10.1182/bloodadvances.2020002657

25. Cheng Y, Mohammed S, Okoh A, et al. Association of blood type on clinical outcomes in Black/African Americans hospitalized for COVID-19 infection. Blood. 2020;136(Supplement 1):14. doi:10.1182/blood-2020-137556

26. Ge H, Wang X, Yuan X, et al. The epidemiology and clinical information about COVID-19. Eur J Clin Microbiol Infect Dis. 2020;39(6):1011-1019. doi:10.1007/s10096-020-03874-z

27. Pan A, Liu L, Wang C, et al. Association of public health interventions with the epidemiology of the COVID-19 outbreak in Wuhan, China. JAMA. 2020;323(19):1915. doi:10.1001/jama.2020.6130

28. Reilly JP, Anderson BJ, Mangalmurti NS, et al. The ABO histo-blood group and AKI in critically ill patients with trauma or sepsis. Clin J Am Soc Nephrol. 2015;10(11):1911-1920. doi:10.2215/CJN.12201214

29. Sharma G, Volgman AS, Michos ED. Sex differences in mortality from COVID-19 pandemic. JACC Case Rep. 2020;2(9):1407-1410. doi:10.1016/j.jaccas.2020.04.027

30. Dehingia N, Raj A. Sex differences in COVID-19 case fatality: do we know enough? Lancet Global Health. 2021;9:e14-e15. doi:10.1016/ S2214-109X(20)30464-2

31. Joe W, Kumar A, Rajpal S, Mishra US, Subramanian SV. Equal risk, unequal burden? Gender differentials in COVID-19 mortality in India. J Glob Health Sci. 2020;2(1):e17. doi:10.35500/jghs.2020.2.e17

32. El-Shitany NA, El-Hamamsy M, Alahmadi AA, et al. The impact of ABO blood grouping on COVID-19 vulnerability and seriousness: a retrospective cross-sectional controlled study among the Arab community. Int J Environ Res Public Health. 2021;18(1):276. doi:10.3390/ijerph18010276 
33. Hoiland RL, Fergusson NA, Mitra AR, et al. The association of ABO blood group with indices of disease severity and multiorgan dysfunction in COVID-19. Blood Adv. 2020;4(20):4981-4989. doi:10.1182/ bloodadvances. 2020002623

34. Goel R, Bloch EM, Pirenne F, et al. ABO blood group and COVID-19: a review on behalf of the ISBT COVID-19 working group. Vox Sang. 2021;17:22.

35. Zahid U, Ramachandran P, Spitalewitz S, et al. Acute kidney injury in COVID-19 patients: an inner city hospital experience and policy implications. Am J Nephrol. 2020;51(10):786-796. doi:10.1159/ 000511160
36. Zeng X, Fan H, Lu D, Huang F, Meng X, Li Z. Association between ABO blood groups and clinical outcome of coronavirus disease 2019: evidence from two cohorts. Medrxiv. 2020. Available form: https:// www.medrxiv.org/content/10.1101/2020.04.15.20063107v1.

37. Zietz M, Zucker J, Tatonetti NP. Associations between blood type and COVID-19 infection, intubation, and death. Nat Commun. 2020;11(1):1-6. doi:10.1038/s41467-020-19623-x

\section{Publish your work in this journal}

The Journal of Multidisciplinary Healthcare is an international, peerreviewed open-access journal that aims to represent and publish research in healthcare areas delivered by practitioners of different disciplines. This includes studies and reviews conducted by multidisciplinary teams as well as research which evaluates the results or conduct of such teams or healthcare processes in general. The journal covers a very wide range of areas and welcomes submissions from practitioners at all levels, from all over the world. The manuscript management system is completely online and includes a very quick and fair peer-review system. Visit http://www.dovepress.com/testimonials. php to read real quotes from published authors. 